\title{
Behavior of some steels at vibrorolling
}

\author{
Gheorghe Nagîț ${ }^{1}$, Oana Dodun ${ }^{1, *}$, Laurențiu Slătineanu ${ }^{1}$, and Marius Ionuț Rîpanu ${ }^{1}$ \\ ${ }^{1}$ Gheorghe Asachi Technical University of Iași, Department of Machine Manufacturing Technology, \\ 700050 Iași, România
}

\begin{abstract}
The vibrorolling could be sometimes applied as a finishing method to diminish the height of the surface asperities. It is expected that the mechanical characteristics of the workpiece material affect in a certain extent the generation of the new profiles corresponding to the surface roughness and distinct values of the surface roughness parameters could be obtained. An experimental research was designed and achieved taking into consideration some vibrorolling process input factors and distinct steels as materials for the test samples. The experimental results were mathematically processed and empirical models were determined. These mathematical empirical models highlight the distinct behavior of the studied steels evaluated by means of the $R a$ surface roughness parameter.
\end{abstract}

\section{Introduction}

There are various reasons which need the finishing of metallic parts surfaces. Thus, in order to ensure a low value for the friction coefficient corresponding to surfaces which moves one other, usually a low surface roughness is necessary. In the case of interference fits, the surface roughness should be diminished up to certain values, but not too low, in order to not diminish the clamping force. Sometimes, the parts superficial layers must have certain specific properties, like high hardness, high crushing strength, corrosion resistance, certain internal stresses etc. In all such situations, adequate finishing methods should be applied in the final part of the technological route.

In order to obtain only low values of the surfaces asperities heights, abrasive finishing methods or finishing methods based on the use of metallic cutting tools could be applied. When the surface layer has to be characterized by an increased hardness compared with the rest of part, certain burnishing or rolling processes could be applied to metallic workpieces. With this aim in view, the surface layer is pressed by means of balls or rolls tools, so that the surface asperities are plastically deformed, and a low surface roughness could be thus obtained [1-5]. Additionally, the plastic deformation of the metallic crystals found in the workpiece surface layer could determine an increase of the hardness and, in this way, an increase of the mechanical strength corresponding to this layer. In such situations, the quality of the surface layer could be evaluated by means of the surface roughness parameters, of the surface layer hardness, of the stress state corresponding to the workpiece surface layer.

* Corresponding author: oanad@tcm.tuiasi.ro 
The surface roughness could be defined as the assembly of surface asperities characterized by a ratio between width and height lower than 50 (some specialists take into consideration a ratio of 40). There are various parameters designed to be used when the problem of surface roughness evaluation is considered, but currently the arithmetic mean deviation of the profile is used.

The surface roughness parameter $R a$ could be determined as the arithmetical mean of the absolute values of the profile deviations from the so-called mean line of the roughness profile.

As above mentioned, the surface rolling supposes the plastic deformation of the surface asperities by means of balls or rolls, which rotates in contact with the surface layer and exert a certain pressure on this surface layer. In order to increase the effects of rolling, the specialists proposed processing methods in which an additional vibration motion is achieved by the deformation tool and this processing method was named vibrorolling or vibroburnishing. Even from its initial proposal, the vibrorolling was investigated by the researchers, in order to find combinations of process input factors values able to ensure convenient values for the process output parameters.

Thus, in the former Soviet Union, Odintsov [3] and Schneider [4] developed ample researches to investigate how various process input factors exert influence on process output parameters, such are the surface roughness or the surface layer hardness.

In the Polish university from Rzeszow, the professor M. Korzynski together his collaborators designed and achieved various equipment for vibroburnishing and investigated also aspects concerning the results of this processing method [5].

The objective of the researches presented in this paper is to highlight some differences between certain steels used in machine building, if workpieces made of these steels are affected by a vibrorolling process.

\section{Phenomena specific to vibrorolling}

In order to materialize a vibrorolling process, the processing scheme from Figure 1 could be applied. The case of vibrorolling by means of a universal lathe could be taken into consideration. A cylindrical workpiece clamped in a universal chuck and in a live center is trained in a rotation movement, specific usually to the turning process. On the lathe apron, a device able to generate the force necessary to the vibrorolling process and to ensure the additional vibratory motion to the vibrorolling tool is placed. Thus, a force $F$ of known value is exerted on the workpiece surface. As a vibrorolling tool, a ball of known radius and made of a hard material is used. Together with the vibrorolling device, the lathe apron achieves a common longitudinal feed movement $f_{l}$.

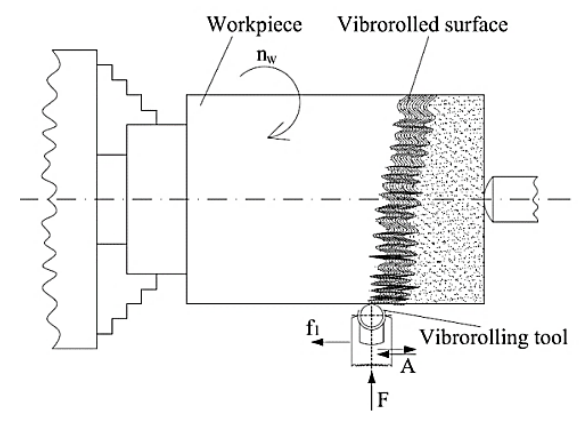

Fig. 1. Schematic representation of vibrorolling process applied to a cylindrical surface corresponding to a metallic workpiece 
The vibrorolling device placed on the lathe apron must ensure also an additional vibratory movement of amplitude $A$ and frequency $f$. If the force $F$ is high enough, the vibrorolling tool will plastically deform the superficial layer of the workpiece, penetrating in the workpiece material on a depth $a_{p}$. If the vibratory motion does not exist, due to the rotation movement of the workpiece and the apron feed motion, the ball will follow a spiral trajectory on the workpiece surface. When the vibratory movement is also present, a more complex trajectory is achieved on the workpiece surface (Fig. 1) and sometimes, two consecutive routes followed by the ball on the workpiece surface could be partially superposed.

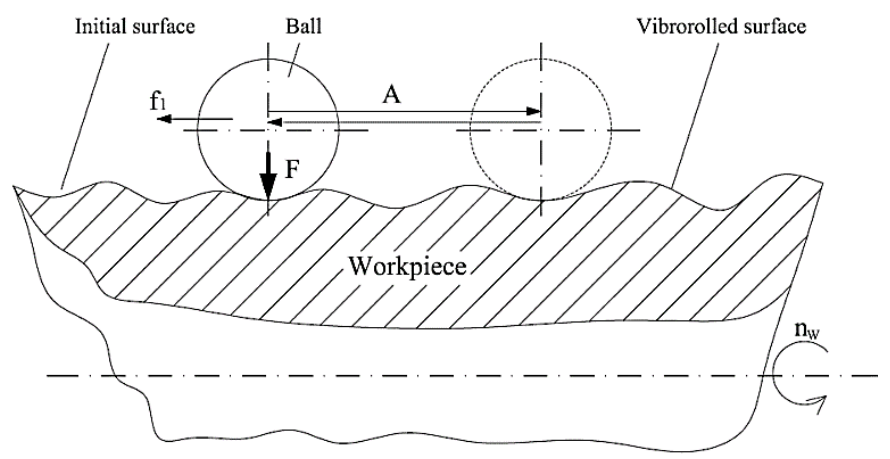

Fig. 2. Detail form the vibrorolling zone.

During the movements achieved on the workpiece surface and due to the force $F$, the surface asperities are affected by a plastic-elastic deformation process. As a consequence of the plastic deformation process, the height of the asperities diminishes (Fig. 2) and the surface roughness parameters could highlight this phenomenon. Due to the elastic component of the deformation process, after the ball passing on the workpiece surface, a certain recovery process develops.

The vibrorolling process will determine not only the decrease of the asperities height, but also a hardening of the workpiece surface layer and this result could be highlighted by measuring the evolution of the material hardness in the workpiece surface layer.

Within this paper, only the changes of the surface roughness as a consequence of the vibrorolling process application will be taken into consideration.

There are some main groups of factors able to affect the surface roughness parameters as a consequence of applying the vibrorolling process: 1) The physical and geometrical characteristics of the deformation ball (ball radius, ball surface roughness parameters, ball material hardness etc.); 2) The kinematic scheme of the vibrorolling process; in the case of vibrorolling cylindrical surfaces of metallic workpiece, the workpiece rotation speed and the apron feed speed could affect the values of the vibrorolled surface roughness parameters; 3 ) The physical and mechanical properties of the workpiece material (hardness, plasticity, tensile strength, relative elongation etc.). 4) The presence and the nature of media used in order to decrease the friction phenomena.

It is expected that as a consequence of the plastic deformation process by vibrorolling process applied to metallic workpieces surfaces, a diminishing of the values of the surface roughness parameters could be highlighted. Practically, under the action of the pressure exerted by the ball, the material corresponding to the asperities is affected by a process of re-distribution by the displacement of the material to the bases of the asperities. 


\section{Experimental research}

In order to investigate the behavior of some steels as a consequence of applying the vibrorolling process, an experimental research was designed and materialized [6].

As scheme of the vibrorolling process that was illustrated in Figure 1 was used. A universal lathe was taken into consideration as equipment for training the workpiece in a rotation movement and for achieving the apron feed movement.

A device able to ensure a vibration movement with pre-established frequency and amplitude was placed and clamped on the lathe apron.

Table 1. Experimental conditions and results

\begin{tabular}{|c|c|c|c|c|c|c|c|}
\hline \multicolumn{8}{|c|}{ Rotation speed $n_{t p}$ of the test piece: $n_{t p}=100 \mathrm{rev} / \mathrm{min}$} \\
\hline \multicolumn{8}{|c|}{ Longitudinal feed $f_{l}=0.024 \mathrm{~mm} / \mathrm{rev}$} \\
\hline \multicolumn{8}{|c|}{ Frequency $f$ of tool oscillation motion: $f_{\min }=5.83 \mathrm{~Hz} ; f_{\max }=15.66 \mathrm{~Hz}$} \\
\hline \multicolumn{8}{|c|}{ Diameter of ball used as a deformation tool: $d_{\min }=6.75 \mathrm{~mm} ; d_{\max }=15.85 \mathrm{~mm}$} \\
\hline \multicolumn{8}{|c|}{ Oscillations amplitude: $A_{\min }=0.6 \mathrm{~mm} ; A_{\max }=1.6 \mathrm{~mm}$} \\
\hline \multicolumn{8}{|c|}{ Force exerted by deformation element: $F_{\min }=100 \mathrm{~N} ; F_{\max }=600 \mathrm{~N}$} \\
\hline \multirow{2}{*}{$\begin{array}{l}\text { Exp. } \\
\text { no. }\end{array}$} & \multicolumn{4}{|c|}{ Process input factors } & \multicolumn{3}{|c|}{$R a, \mu \mathrm{m}$, for distinct steels } \\
\hline & $f, \mathrm{~Hz}$ & $R, \mathrm{~mm}$ & $A, \mathrm{~mm}$ & $F, \mathrm{~N}$ & $1 \mathrm{C} 45$ & E 335 & $\begin{array}{c}18 \mathrm{MnCr} \\
4-4\end{array}$ \\
\hline 1 & 5.83 & 6.75 & 0.6 & 100 & 0.07 & 0.05 & 0.04 \\
\hline 2 & 5.83 & 6.75 & 0.6 & 600 & 0.02 & 0.03 & 0.05 \\
\hline 3 & 5.83 & 6.75 & 1.6 & 100 & 0.65 & 0.61 & 0.55 \\
\hline 4 & 5.83 & 6.75 & 1.6 & 600 & 0.25 & 0.30 & 0.40 \\
\hline 5 & 5.83 & 15.85 & 0.6 & 100 & 0.03 & 0.02 & 0.02 \\
\hline 6 & 5.83 & 15.85 & 0.6 & 600 & 0.01 & 0.01 & 0.02 \\
\hline 7 & 5.83 & 15.85 & 1.6 & 100 & 0.24 & 0.23 & 0.20 \\
\hline 8 & 5.83 & 15.85 & 1.6 & 600 & 0.10 & 0.14 & 0.20 \\
\hline 9 & 15.66 & 6.75 & 0.6 & 100 & 0.04 & 0.03 & 0.02 \\
\hline 10 & 15.66 & 6.75 & 0.6 & 600 & 0.02 & 0.02 & 0.03 \\
\hline 11 & 15.66 & 6.75 & 1.6 & 100 & 0.42 & 0.50 & 0.46 \\
\hline 12 & 15.66 & 6.75 & 1.6 & 600 & 0.11 & 0.16 & 0.18 \\
\hline 13 & 15.66 & 15.85 & 0.6 & 100 & 0.02 & 0.01 & 0.01 \\
\hline 14 & 15.66 & 15.85 & 0.6 & 600 & 0.01 & 0.01 & 0.01 \\
\hline 15 & 15.66 & 15.85 & 1.6 & 100 & 0.12 & 0.09 & 0.08 \\
\hline 16 & 15.66 & 15.85 & 1.6 & 600 & 0.06 & 0.07 & 0.10 \\
\hline
\end{tabular}

The force necessary to the vibrorolling process was ensured by means of a spring, for which a previous calibration operation allowed establishing a correspondence between the applied force and the diminishing of the spring length.

A full factorial experiment with four independent variables at two levels was considered. One appreciated that within the experimental interval of independent variables variation, there will be a monotone variation of the response function ( $R a$ surface roughness parameter) and, in such a situation, only two levels of the independent variables could be taken into consideration. On the base of some preliminary experiments, the values for the process input factors were established: these values, together with other initial experimental conditions, were mentioned in the first lines of table 1.

Sleeves shaped test pieces made of three distinct steels were prepared. The sleeves were positioned and clamped on a mandrel that at its turn was clamped in the universal chuck and in a live center. As steels for test pieces, there were used the steel 1C45, as a material 
widely used in the field of machine building and sometimes used as an etalon material when the problem of machinability evaluation is formulated, steel E335, as a material that does not need heat treatment, but able to ensure a certain high tensile strength, and the steel $18 \mathrm{MnCr} 4-4$, as a steel supposing the applying a thermo-chemical heat treatment (carburisation). The surfaces proposed to be vibrorolled were previously obtained by applying a finishing turning, in the same cutting conditions. Even in such a situation, due probably to their distinct machinability by finishing turning, a certain dispersion of values corresponding to the $R a$ surface roughness parameter was observed ( $R a=1.27-1.56 \mu \mathrm{m})$. The surface roughness was measured before and after applying the vibrorolling process by means of a G4 type profilometer-profilograph (Russia).

The values of the input factors were included in the table 1 . In the last three columns of table 1 , the experimentally obtained values of the $R a$ surface roughness parameter were mentioned.

\section{Processing and analyzing the experimental results}

The experimental results were mathematically processed by means of a specialized software [7] based on the method of least squares. In this way, three power type empirical models were obtained. The power type empirical models were preferred since they offer a direct image concerning the influence exerted by each process input factor on the $R a$ surface roughness parameter. As indicator of adequacy of the power type mathematical empirical models to the obtained experimental results, the so-called Gauss criterion could be used.

The power type mathematical empirical models were the following:

$$
R a=32.742 f^{-0.433} R^{-0.98} A^{2.138} F^{-0.530,},
$$

in the case of steel $1 \mathrm{C} 45$ (the Gauss criterion having the value $S_{G}=1.208144 \cdot 10^{-3}$ ),

$$
R a=16.753 f^{-0.514} R^{-1.184} A^{2.411} F^{-0.293},
$$

in the case of steel E 335 (the Gauss criterion having the value $S_{G}=2.484984 \cdot 10^{-3}$ ),

$$
R a=4.754 f^{-0.655} R^{-1.090} A^{2.372} F^{-0.0282,}
$$

in the case of steel $18 \mathrm{MnCr} 4-4$ (the Gauss criterion having the value $S_{G}=4.080313 \cdot 10^{-3}$ ).

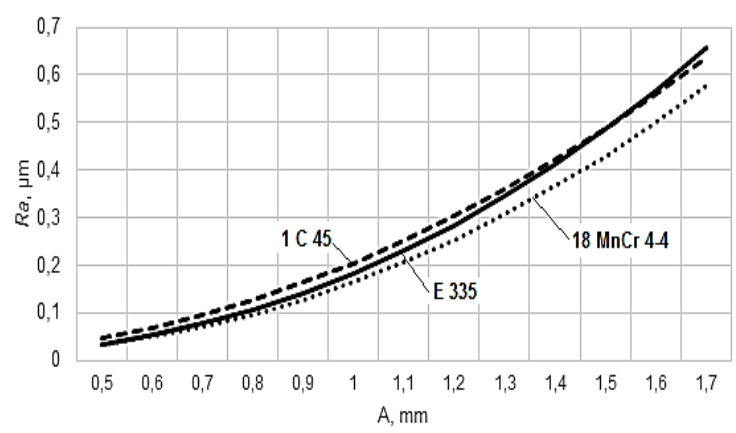

Fig. 3. Influence exerted by the amplitude $A$ of the vibratory movement on the value of the $R a$ surface roughness parameter, in the case of applying vibrorolling process to test pieces made of three distinct steels $(f=5.83 \mathrm{~Hz}, R=6.75 \mathrm{~mm}, F=100 \mathrm{~N})$. 


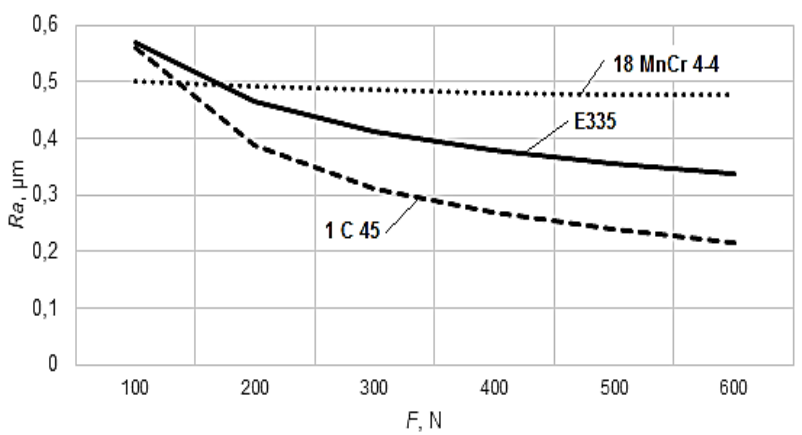

Fig. 4. Influence exerted by the force $F$ on the value of the $R a$ surface roughness parameter, in the case of applying vibrorolling process to test pieces made of three distinct steels $(f=5.83 \mathrm{~Hz}, R=6.75$ $\mathrm{mm}, A=1,6 \mathrm{~mm}$ ).

On the base of these power type mathematical empirical models, the graphical representations from Figures 4 and 5 were elaborated. The analysis of the empirical mathematical models and of the graphical representations allows statement of some remarks concerning the influence exerted by the process input factors on the $R a$ surface roughness parameter. Thus, one could notice that for all the three steels, the most important influence factor is the vibration amplitude A, whose exponent in all empirical models has the maximum absolute value. As a second influence factor, the ball radius $R$ could be mentioned, since the exponent value has the second absolute value in all empirical mathematical models, compared with the absolute values corresponding to the other exponents. As expected, the increase of the frequency $f$, of the ball radius $R$ and force $F$ determines the decrease of the value of $R a$ surface roughness parameter. In the case of steel $18 \mathrm{MnCr} 4-4$, the influence exerted by the force $F$ is not significant (Fig. 4), since the value of the exponent attached to $F$ in the empirical model has a value very near to zero). The steel $18 \mathrm{MnCr} 4-4$ ensures the minimum value of the parameter $R a$ when the influence of the amplitude $A$ is considered (Fig. 3) and a general higher value of the same parameter when the influence exerted by the force $F$ is considered (Fig. 4); probably the presence of the alloying elements manganese and chrome generate such a behavior of this steel.

\section{Conclusions}

One of the processing methods applied in order to decrease the height of the surface asperities is the vibrorolling. Compared with the older burnishing process, the vibrorolling uses an additional vibratory movement of the burnishing tool. An analysis of the burnishing process input factors able to influence the height of the surface asperities showed that these factors could be classified in some groups, taking into consideration the geometrical and mechanical characteristics of burnishing tool, the values of the factors corresponding to vibrorolling kinematic scheme, the characteristics of the workpiece material, the presence and nature of eventual used processing media, the pressure exerted by the vibrorolling tool on the workpiece surface.

An experimental research aiming to highlight the influence exerted by some vibrorolling process input factors (frequency $f$ and amplitude $A$ of vibratory movement, ball radius $R$ and force $F$ ) on the $R a$ surface roughness parameter was designed and materialized. By mathematical processing of the experimental results by means of a specialized software, three mathematical empirical models were determined.

As expected, one noticed that the increase of the process input factors $f, R$ and $F$ determine a decrease of the values corresponding to the $R a$ surface roughness parameter, while the increase of amplitude $A$ generate an increase of the same parameter. In the future, 
there is the intention to extend the experimental research in the direction of a more detailed investigation of the microphenomena developed in the work zone corresponding to the vibrorolling process.

\section{References}

1. A.V. Ezhelev, I.N. Bobrowski, I.N., A.A. Lukyanov (in Russian). Fundamental research, 6 (2012)

2. V. G. Revenko, G. R. Alekseeva, N. F. Stepanov, N. L. Bogdashkina, and G. P. Chernova. Protection of Metals, 38, 1 (2002)

3. V.G. Odintsov. Finishing processing of details by diamond burnishing and vibroburnishing (in Russian) (Mashinostroenie, 1981)

4. I.G. Schneider (in Russian). Stanki i instrument, 7, 34-35 (1972)

5. M. Korzynski and J. Lubas. Bushing texturing by burnishing, in Nonconventional finishing technologies, (Polish Scientific Publishers PWN, Warsaw, 2013)

6. G. Nagît, Theoretical and experimental contributions concerning vibroburnishing process. Doctoral thesis (in Romanian) (Gheorghe Asachi Technical University, Iaşi, 1997)

7. G. Crețu, Fundamentals of experimental research. Laboratory handbook (Technical University of Iaşi, Romania, 1992) 